\title{
Simülasyona Dayalı Hemşirelik Eğitiminde Kuramlar
}

\section{Theories in Simulation-Based Nursing Education}

\begin{abstract}
Ayşe AKALIN ${ }^{\mathrm{a}}$ Sevil ŞAHIN ${ }^{\mathrm{b}}$
ÖZ Simülasyon güvenli ve yapılandırılmış bir ortamda hastaya zarar verme riski olmadan hemşirelik öğrencilerinin öğrenmelerini, uygulama yapmalarını ve deneyim kazanmalarını sağlamaktadır. Hemşirelik eğitiminde simülasyonu tasarlamak, uygulamak ve değerlendirmek için yaygın olarak kullanılan eğitim teorileri bulunmaktadır. Sosyal, bilişsel, deneyimsel ve yapılandırmacı öğrenme kuramları yetişkin öğrenmede önem taşımaktadır. Bunun yanında beceri kazanma modeli, klinik karar verme modeli ve Jeffries simülasyon modeli simülasyona dayalı eğitimde yaygın olarak rehber alınan kuramlardandır. Simülasyona dayalı eğitimin kuramlar rehberliğinde tasarlanması, uygulanması ve değerlendirilmesi ile simülasyon eğitiminde kuramsal alt yapının ortaya koyulması ve güçlendirilmesi böylece hemşirelik eğitiminin niteliğinin arttırılmasına katkı sağlanması beklenmektedir. $\mathrm{Bu}$ derleme makalede, simülasyona dayalı hemşirelik eğitiminde kuramların tanımlanması ve anlaşılması için kapsamlı bir çerçeve sunulması amaçlanmıştır.
\end{abstract}

Anahtar sözcükler: Hemşirelik, simülasyon, öğrenme teorileri

\begin{abstract}
Simulation allows nursing students to learn, practice, and gain experience in a safe and structured environment without risk to patients. Studies suggest that simulation should be based on a theoretical frame work or conceptual model to guide the simulation practice. It is required based on a theoretical frame work or conceptual model for perform more effectively of simulation. There are widely used educational theories for designing, implementing and evaluating simulations in nursing education. Social, cognitive, experiential and constructivist learning theories are crucial to adult learning. In addition novice to expert model, model of clinical judgment and Jeffries simulation theory were the widely-guided theories in simulation-based training. The design, implementation and evaluation of simulation-based learning under theories guidance reveals and reinforces the theoretical background in simulation education. In this context, it is expected contributing to increasing the quality of nursing education. This review article was aimed: provides a comprehensive frame work for understanding and identification of theories in simulation-based nursing education.
\end{abstract}

Keywords: Nursing, simulation, learning theories

\section{Giriş}

Hemşirelikte yenilikçi bir öğretim stratejisi olan simülasyon eğitimi, güvenli ve yapılandırılmış bir ortamda, hastaya zarar verme riski olmadan, öğrencilerin aktif olarak eğitimlere katıldığı bir öğrenme sürecidir (1-3). Bu öğrenme sürecinin etkin bir biçimde yapılabilmesi için simülasyon yönteminin kanıta dayalı bilimsel gelişmelere dayandirılarak ve kuramlar rehberliğinde yürütülmesi önem taşımaktadır $(4,5)$. Standardize edilmiş bir simülasyon tasarımı ise etkin bir simülasyon yaklaşımı için bir çerçeve sağlamaktadır (6). Bu kapsamda; Uluslararası Klinik Simülasyon ve Öğrenme Hemşirelik Birliği (The International Nursing Association for Clinical Simulation and Learning-INACSL) hemşirelik eğitiminde simülasyonun tüm aşamalarında rehber olarak alınması için "En İyi Uygulama Standartları'nı yayınlamıştır (7). Simülasyonda en iyi uygulama standartlarının da tanımlanmış olması kullanılan simülasyon yöntemlerinin daha bütüncül ve sistematik olma yolunda ilerlemesine katk1 sağlamaktadır (6-7). Bunun yanında kuramsal alt yapının da ortaya konulma ve güçlendirilme gereksinimi giderek artmaktadır. Literatürde, simülasyon yöntemi ile öğrenme pek çok farkl1 yaklaşım ve kuram/model ile desteklenmektedir $(4,5)$. INACSL'de simülasyon yaklaşımının teorik bir çerçeve yada kavramsal bir modele dayandırılmasını önermektedir (7). Hemşirelik eğitiminde simülasyonun öğrenme kuramları

Geliș Tarihi/Received: 23-03-2018 / Kabul Tarihi/Accepted: 26-10-2018

aDoktora Öğrencisi, Ankara Yıldırım Beyazıt Üniversitesi, Sağlık Bilimleri Enst., e-posta: ayse-akalin @ hotmail.com, ORCID: 0000-0002-9575-7537.

bDr. Öğr. Üyesi, Ankara Yıldırım Beyazıt Üniversitesi, Sağlık Bilimleri Fakültesi, e-postal: sevilsahin1@gmail.com, ORCID: 0000-0001-7089-6648

Sorumlu Yazar/Correspondence: Doktora Öğrencisi, Ankara Yıldırım Beyazıt Üniversitesi Sağlık Bilimleri Enstitüsü, e-posta: ayseakalin@ hotmail.com ORCID: 0000-0002-9575-7537

Atıf: Akalını A, Şahin S. Simülasyona Dayalı Hemşirelik Eğitiminde Kuramlar. Sağlık Bilimleri ve Meslekleri Dergisi 2019;6(1):136-143

Citation: Akalını A, Şahin S. Theories in Simulation-Based Nursing Education. Journal of Health Science and Profession 2019;6(1):136-143 
rehberliğinde tasarlanması, uygulanması ve değerlendirilmesi ise; öğrencilerin simülasyon eğitimlerindeki kazanımlarına katkı sağlamaktadır $(3,5)$. $\mathrm{Bu}$ derlemede; simülasyonun tasarımı, uygulaması ve değerlendirilmesinde rehber olabilecek kuramların tanımlanması ve literatüre katkı sağlanması amaçlanmıştır.

\section{Sosyal Öğrenme Kuramı}

Simülasyon uygulamalarında sosyal öğrenme kuramcılarından, öz yeterlilik ya da gözlemsel öğrenmenin davranışların kazandırılmasında önemli olduğunu savunan Bandura referans gösterilmektedir. Bandura'nın kuramında davranışları gözlemleyerek öğrenme ve modelleme esas alınmakta olup, gözlem yoluyla öğrenme yalnızca bireyin diğerlerinin davranışlarını taklit etmesi değil, aynı zamanda çevresindeki olayları bilişsel süreçlerle kavramasıyla oluşan bilgi kazanımı olarak tanımlanmaktadır $(8,9)$. Fakat Bandura; modelleme ve gözlemin insanın öğrenmesini açıklamada yetersiz kaldığını düşünerek kuramını daha sonra düşünme, hafıza, dil ve davranışların sonuçlarını tahmin etme ve değerlendirme gibi bilişsel süreçleri de içine alacak biçimde genişletmiştir. Bu bakımdan, kuramda gözlem ve modelleme yoluyla öğrenmenin yanında bilişsel boyutun da önem taşıdığı ortaya çıkarılmıştır (10). Bandura'nın kuramına göre simülasyonun tasarlanması ve planlanmasında edimsel koşullanma ve davranışçılık ilkelerine odaklanılmaktadır. $\mathrm{Bu}$ kapsamda simülasyon öncelikle bilgi yada beceriyi kazandırmak için tasarlanmakta, diğer aşamada ise kazanılan bilginin güçlendirilmesi hedeflenmektedir.

Hemşirelik öğrencileri uygulama eğitimlerinde çoğunlukla eğiticinin davranışlarını, uygulamalarını ve uygulama tekniklerini gözlemleme ve modelleme eğilimindedir. Fakat günümüzde simülasyonun öğrenme yaklaşımı olarak kullanılması ile uygulamaları hasta üzerinde deneyimleyerek öğrenen hemşireler yerini, uygulamaları gerçeğe en yakın özelliklerde deneyimleyerek klinik yeterlilik kazanmış hemşirelik öğrencilerine bırakmaktadır. Sosyal ögrenme kuramı açısından değerlendirildiğinde, simülasyon uygulamaları ile öğrenciler birbirlerine ya da eğiticiler öğrencilerine doğru bilgi ve becerilerin kazanılmasında rol model olabilmektedir. Bu kapsamda, gerçeğe en yakın biçimde oluşturulmuş çevrede bilginin kazanılmasının artırılmasında rol modelleme davranışı ile gözlemsel öğrenme birlikte kullanılabilmektedir $(11,12)$.

\section{Bilişsel Öğrenme Kuramı}

Gestalt psikologlarıyla başlayan öğrenmedeki bilişsel süreçlere yönelik çalışmalar daha sonra Piaget, Bruner, Ausubel gibi psikolog ve eğitimcilerin katkıları ile giderek gelişmiş ve bilişsel kuramlar olarak tanımlanmıştır. Bilişsel ögrenme kuramına göre öğrenme, zihinsel bir süreç olarak görülmekte ve bireyin katılımını gerektirmektedir. Bilişsel kuramcılar daha çok anlama, algılama, düşünme ve yeniden üretme gibi kavramlara odaklanmakta ve temel bilgiyi dışsal etmenlere değil, öğrencinin içsel olarak kullandiğ 1 bilişsel süreçlere yöneltmektedir. Bilişsel kuramcılar öğrenmeyi, kişinin zihninde meydana gelen değişikliğin dışa yansıması olarak tanımlamakta ve gözlenebilir davranışların ötesinde gözlenemeyen bilişsel süreçlerle açıklamaktadır $(13,14)$.

Simülasyonu deneyimleyen öğrencilerin eğitim sürecinde bilişsel öğrenme kuramı gözlemlenebilmektedir. Bilişsel öğrenme; öğrenmeyi kontrol eden içsel bir süreçtir ve eğiticiler simülasyon uygulamasında öğrencinin önceki bilgilerinden faydalanmaktadır. $\mathrm{Bu}$ yolla bilişsel öğrenme teorisinin temel bileșenleri simülasyon uygulamasında kendini ortaya koymaktadır. Simülasyon ile öğrenmede; algılama, önceki bilgilerle karşılaştırma, yeni bilgileri oluşturma, elde edilen bilgileri belleğe depolama ve zihinsel ürünlerin mantık yönünden değerlendirilmesi ile bilişsel öğrenme kuramı uygulanmış olmaktadır. Örneğin; öğrenciler simülasyon deneyimi ile yeni bilgiyi öğrenmekte ve çözümleme oturumları aracılığ 1 ile yaptığı uygulamalar üzerinde düşünme ve değerlendirme yapma firsatı elde ederek bilgiyi yeniden özümsemekte ve önceki bilgileri ile karşılaş-tırabilmektedir. Böylece öğrencilerin simülasyon deneyimlerinde bilişsel öğrenme kuramına dayandırılarak yeterli ve nitelikli öğrenmenin elde edilmesine katkı sağlanmaktadır (15).

\section{Yapılandırmacı Öğrenme Kuramı}

Yapılandırmacı kuram; bireylere daha çok düşünmeyi, anlamay1, kendi ögrenmelerinden sorumlu olmayı ve kendi davranışlarını kontrol etmeyi öğrenmeleri gerektiğini vurgulamaktadır. Kuramın temeli; başkalarının bilgilerini olduğu gibi 
bireylere aktarmak yerine, bireylerin kendi bilgilerini, kendilerinin yapılandırması gerektiği görüşüne dayanmaktadır. $\mathrm{Bu}$ kuramda bilginin transferi ve bilginin yeniden yapılandırılması önem taşımaktadır $(16,17)$.

Kurama göre öğrenme, zihinsel bir süreç olarak tanımlanmaktadır. Öğrenme sürecinde bilginin yeniden yapılandırılması ise; yeni bilgilerle önceki bilgiler arasında bağlantı kurulması ile gerçekleşmektedir. Buna göre öğrenme, bilginin doğrudan aktarılması ile gerçekleşmeyip bireyden bilgiyi kendisinin yapılandırması beklenmektedir (18-20). Bu açıdan, simülasyon ile yapılandırmacı öğrenme kuramının birçok yönden bağlantısı bulunmaktadır. Simülasyon ile öğrencilerin şuan ki simülasyon uygulamaları ile gelecekteki hasta ile olacak klinik deneyimleri arasında bilginin yapılandırılması sağlanmakta ve aktif öğrenme için bir çevre oluşturulmaktadır (21). Günümüz gereksinimlerine yönelik olarak ise hemşirelik eğitim programlarında bilimsel bir yaklaşım olan hemşirelik süreci kullanılarak, bilginin ezberlenerek öğrenilmesinin yerine sorgulayarak ve bilgiyi üreterek öğrenen nitelikli profesyonel hemşirelerin yetiştirilmesi amaçlanmaktadır. Ayrıca, eğitim programlarında mevcut bilgilerden yeni bilgilerin üretilmesi ve bilginin yeniden yapılandırılması önem kazanmaktadır. $\mathrm{Bu}$ kapsamda hemşirelik eğitiminde simülasyon kullanımı yapılandırmacı yaklaşımın bu temel felsefesi yönünden önem taşımaktadır $(22,23)$.

Bilginin yapılandırılmas1 bireysel ya da sosyal yapılandırmacı uyumdan da kaynaklanabilmektedir. Bu kapsamda simülasyon ile bir kişi ya da bir grup öğrenciye sağlanan öğrenme ortamı ile öğrenci ile diğer öğrenciler ve eğitici arasında ya da eğitici ve öğrenci arasında iletişim ve ortak öğrenme süreci sağlanmaktadır. Ayrıca simülasyon uygulamasındaki çözümleme oturumlarında öğrenci grubu ya da öğrenciye, "uygulamadan ne kazand1, ne öğrendi, başka ne yapabilirdi ve daha farklı nasıl düşünebilirdi" soruları ile deneyimlerini ya da edindiği bilgiyi yapılandırma fırsatı da sağlanmaktadır (19).

\section{Deneyimsel (Yaşantısal) Öğrenme Kuramı}

Deneyimsel öğrenme kuramı öğrenmeyi, "bilginin deneyimler yoluyla oluşması süreci" olarak tanımlayan David Kolb tarafindan geliştirilmiştir. Amerikalı psikolog ve eğitim kuramcısı Kolb'a göre bireyler kendi deneyimlerinden öğrenir ve bu öğrenmenin sonuçları güvenilir bir şekilde değerlendirilebilir (20). Kurama dayalı yapılan simülasyonlar ile öğrenen birey, gerçeğe yakın yapay bir deneyim elde etmektedir. Bu deneyim öğrenenin kendisini keşfetmesine, söz konusu temayı yaşayarak öğrenmesine ve belki de en önemlisi içselleştirmesine olanak tanımaktadır $(21,24)$.

Kurama dayalı simülasyon eğitiminde; başlangiçta öğrencilerin öğrenme tercihlerinin ne olduğuna yönelik ön uygulama yapılmakta ve sonrasında ise öğrenciler simülasyon uygulamasına katılmaktadır. Simülasyonun etkinliği ise öğrencilerin simülasyona dayalı öğrenme metoduna yönelik neler düşündükleri ve deneyimlerinden neler kazandıklarını tartışmaları ile tamamlanmaktadır. Böylece deneysel öğrenme aracılığıyla kazanılan deneyimlerin gerçek yaşamdaki benzer durumlara transferi ile yapılandırılması sağlanarak öğrenciye "daha farklı nasıl düşünülebilir ya da eylemde bulunulabilir" kazanımı sağlanmaktadır (21,24-26). Böylece öğrenme yalnızca simülasyonun uygulama aşamasında değil çözümleme süreci ve sonrasında da öz değerlendirmeyle yansitici olarak devam etmektedir.

John Dewey'de yaparak yaşayarak öğrenmeye ve tecrübeye önem vermekte ve bilginin deneyime dayalı yaşantılar sonucu daha iyi öğrenileceğini savunmaktadır. Dewey 1859-1952 yıllan arasında yaşamış olan ünlü Amerikan filozof ve eğitimcisidir. İnsanların birbirinden öğrenmesi olgusuna ilk dikkat çeken kişi olmuştur. Eğitim kuramında da öğrencinin kişiliğine göre hareket edilmesi gerektiğine işaret etmektedir. Öğrencilere bilginin değerini kabul ettirmek ve ögrencinin bilgiye ilgi duymasını sağlamanın yanında, toplumsal olayları gözlemlemesi ve gözlemlerini nasıl değerlendireceğinin öğretilmesi gerektiğini savunmaktadır (27). Benzer şekilde simülasyon çalışmaları, öğrenmenin deneyimleyerek ortaya çıktığını ileri sürmektedir. Dewey bilginin düşünülen değil yapılanlardan ve yaşanılanlardan oluştuğunu ileri sürmektedir. Böylece eğitimi, yaşam boyu süren bir eylem olarak değerlendirip, yapılan her şeyi yaşamdaki etkileriyle ölçmektedir (28).

Dewey'in eğitim kuramı öğrencinin neyi bildiğini, neyi bilmediğini ve neyi öğrenmesi gerektiğini bildiğini varsaymaktadır. Bu varsayımı simülasyon modelinde eğitimcinin geri bildirim verme rolünün önemini ortaya çıarmaktadır. 
Literatürde de, simülasyonun etkili olmasının öğrencilerin tasarımdaki rollerine bağlı olduğu vurgulanmaktadır. $\mathrm{Bu}$ kapsamda simülasyon uygulamasında öğrencilerden geri bildirim alınmasına yada öğrenciye geri bildirim verilmesine vurgu yapılmaktadır. Böylece öğrenme deneyiminde, öğrencinin kazanımı artırılırken öğrenciler tarafından yapılan geri bildirimler aracılığıyla daha sonraki simülasyon tasarımlarına da yön verilebilmektedir (28-30).

\section{Yetişkin Öğrenme Kuramı}

Pedagoji, çocuklara ilişkin uygulamalı ve kuramsal eğitim bilimi ve sanatıdır. Pedagoji, öğretmen odaklı eğitimi tanımlamaktadır. Malcolm Knowles ise öğrencilerin öğrenmelerine yardımcı olma bilimi ve sanatı olarak "androgoji" kavramını tanımlamıştır. Knowles, bu kavramı yetişkin öğrenmelerine ilişkin kuramını açıklamak için kullanmaktadır. Ayrıca kuramını, yetișkin ve yetişkinlik öncesi öğrenmenin birbirinden farklı olduğuna dayandırmaktadır. Knowles'ın yetişkin öğrenme kuramında öz (kendini) yönlendirme ve motivasyon kavramları yetişkin öğrenmesinin temel bileşenlerindendir. $\mathrm{Bu}$ temel bileşenlere göre, bilme ve öğrenme ihtiyacı yetişkin ögrenenlerin öğrenme motivasyonunu artıran temel bir bileşendir. $\mathrm{Bu}$ kapsamda öğrenenlerin deneyimleri, aslında yetişkin öğrenenleri güdüleyen en zengin kaynaklardan biridir. Özyönlendirme ise bireyin sahip olduğu sosyal yeteneklerden biridir. Bireyler olgunlaştıkça kendi kendilerini yönlendirmeye eğilimlidirler. Özyönlendirme gücü yüksek olan bireyler ise karşılaştıkları durumlar karşısında neyin uygun olduğunu bilmekte ve buna göre karar verebilmektedir $(31,32)$.

Knowles'1n Yetişkin Öğrenme Kuramı'na dayalı tasarlanmış bir simülasyonda öğrencilerin öz yönlendirmeli öğrenme hedeflerini belirlemeleri beklemektedir. Çünkü yetişkinler yeterliliğe dayalı öğrenicidir. Bu açıdan, yetişkinler doğrudan kendi koşullarına yararcı biçimde uygulayabilecekleri bir beceriyi öğrenmek ya da bilgiyi edinmek istemektedir. Bir simülasyon tasarımında ise sonuçlar, öğrencilerin hedefleri doğrultusunda önceden belirlenmektedir. Belirlenen hedefler doğrultusunda ise yetişkin öğrenciler başarılı olmak için motive olmaktadır. Ayrıca simülasyon tasarımında, öğrencilerin motivasyonları, düşünce biçimleri ve yaklaşımları önce ölçülmekte daha sonra ise simülasyon tasarımıyla eşleştirilmektedir. Hedef, öğrencinin başladiğı yerden hedeflenen noktaya ulaştığında bilgisini artırabilecek bir simülasyonun oluşturulmasıdır. Buna göre öğrencilerin yetişkin öğreniciler gibi amaçları ve ulaşmak istedikleri hedefleri arasında eşleşen bir öğrenme etkinliğine katıldıklarında daha iyi performans göstereceklerini varsayılmaktadır (33-35). Bu nedenle, simülasyonun geliştirilmesi ve değerlendirilmesinin temelleri olarak Knowles'ın yetişkin öğrenme kuramını kullanacak eğitimcilerin öğrencinin bir ön değerlendirmesini yaparak simülasyon tasarımını ilerletmesi ve uygulama aşamasına getirmesi önem taşımaktadır.

\section{Beceri Kazanma Modeli}

Patricia Benner Beceri Kazanma Modeli'nde, hemşirelerin beceri kazanma sürecini acemilikten uzmanlığa doğru beş aşamaya ayırmaktadır. Modelde așamalar arasındaki farkları hemșirelerin ilgi odakları, uygulamaya katılımları ve sorumluluk algıları oluşturmaktadır. İlk aşamada acemi hemşire ilgisini yaşamsal bulgular gibi objektif davranışlara odaklamaktadır. İkinci aşamada, deneyimli hemşire belirti ve bulguların olası hastalık ile bağlantısını kurabilecek ve aradaki ilişkiyi fark edebilecek kadar uygulama deneyimine sahiptir. Üçüncü aşama olan yetkili hemşire, hemşirelik uygulamalarının hasta bakımı üzerine etkisini daha geniş bir perspektifle değerlendirmeye başlamıştır ve sorumluluk duygusu gelişmiştir. Dördüncü aşamasında hemşire yetkinlik seviyesine ulaşmıştır. Uzmanlık aşamasına ulaşan hemşire ise geçmiş deneyimlerinin rehberliğinde durum ve koşulların anlaşılmasında derin bir anlayışa sahip ve buna göre davranmaktadır $(36,37)$.

$\mathrm{Bu}$ model hemşirelik eğitimindeki simülasyon uygulamalarında hem eğiticilerin hem de ögrencilerin eğitiminde uygulanabilir bir modeldir. Doğan ve Kuğuoğlu'na göre hemşirelik eğiticileri yüksek gerçeklikte hasta simülatörleri ile verecekleri eğitimleri nasıl vereceklerini öğrenmeye başladıklarında Benner' in acemilik evresinden başlayarak ilerleyeceklerdir. Bu eğitimciler, deneyimli ve uzman olsalar dahi başlangıçta simülasyon yaklaşımının eğitimde uygulanmasında acemi düzeydedirler. Simülasyonun hazırlanması, uygulamanın yürütülmesi ve çözümleme sürecinin yürütülmesine yönelik bilgi ve deneyim kazanmaları için belirli aşamalara gereksinim 
duyacaklardır. Bu nedenle simülasyon bu model kapsamında; hem eğitimcilerin hem de hemşirelik öğrencilerinin acemilikten uzmanlık aşamasına ulaşıncaya kadar planlı kapsamlı eğitimlerle alanlarındaki yetkinliklerinin arttırılmasında önemli bir rehber niteliğindedir (22).

\section{Klinik Karar Verme (Yargılama) Modeli}

Klinik Karar Verme; Tanner tarafindan bir klinik durumu tanıma, yorumlama, buna uygun olarak girişimde bulunma ve girişimlerin sonucu üzerinde düşünüp yansıtma olarak tanımlanmıştır. Ayrıca Tanner, klinik karar vermeyi "bir hemşire gibi düşünme becerisi” olarak da tanımlamaktadır. Tanner modelini, uygulamada hemşirelerin düşünme biçimlerini araştıran 200'ün üzerinde araştırmaya temellendirmektedir. Modelde hemşirelik süreci; tanılama, planlama, uygulama ve değerlendirmeyi içeren dört aşamalı bir bilimsel sürecin uygulanmasıyla öğretilmektedir (38).

Modeldeki dört aşamadan birincisi olan tanılama aşaması; hemşirenin hastanın öyküsünü almas1 ve daha sonra mevcut durumla ilgili ek bilgilerin toplanmasını içermektedir. İkinci aşama olan planlamada hemşirenin; hastanın durumunu ayrıntılı bir şekilde anlayıp uygun klinik yanıtları oluşturmak için elde ettiği bilgiler ile girişimleri planlaması gerekmektedir. Üçüncü aşama olan uygulama aşamasında ise hemşire; hastanın durumunu analiz ederek, müdahale etmeye veya hastanın ihtiyaçlarına cevap vermeye başlayabilmektedir. Son aşama olan değerlendirme aşamasında hemşire, uygulamanın sonuçlarını incelemekte ve tüm sonuçların hastanın durumuna ne kadar uygun olduğunu belirlemektedir $(28,38)$.

Literatürde, eğitimcilerin bu modeli senaryo temelli yüksek gerçekli simülasyon (YGS) uygulamalarında kullandığı vurgulanmaktadır. YGS uygulamalarındaki çözümleme oturumu, ögrencinin hasta sonucunu olumlu ya da olumsuz yönde etkileyen faktörleri tanımasına imkan sağlamaktadır $(39,40)$. Bu oturumda öğrencilerin yansitıcı düşünmesini sağlayabilmek için videoteypler, yüksek sesle düşünme, grup tartışmaları ve diyaloglar kullanılabilmektedir. Böylece, simülasyon eylem sirasinda ve sonrasinda yansitma ile öğrenmeye katkı sağlamaktadır (22).

\section{Jeffries Simülasyon Kuramı}

Jeffries Simülasyon Kuramı "hemşirelik eğitimi simülasyon çerçevesi” (Nursing Education
Simulation Framework-NESF) kapsamında oluşturulmuştur $(1,2)$. Bu kuram simülasyonun tasarımı, uygulanması ve değerlendirilmesi için kavramsal bir çerçeve sunmaktadır (3). NESF eğitici, öğrenci, eğitim uygulamaları, tasarımın özellikleri ve sonuçlar olmak üzere beş ana bileşen üzerine kurulmuştur (1,2). Fakat Jeffries Simülasyon Kuramı'nda bu bileşenler üzerinde minör değişiklikler yapılmıştır. Kuram; içerik, alt yap1 (background), tasarım, simülasyon deneyimi, kolaylaştırıcı ve öğretim stratejisi, katılımcı ve sonuçlar olmak üzere yedi ana bileşenden oluşmaktadır (3).

İçerik; durum ortam gibi içeriksel faktörler, simülasyonun her alanını etkilemekte olup simülasyonun tasarımında veya değerlendirilmesinde önemli bir başlangıç noktasıdır. İçerik; simülasyonun yapılacağ 1 yer (laboratuvar, in situyerinde simülasyon) ve simülasyonun ana amac1 (örneğin simülasyonun değerlendirme amaçlı $\mathrm{m} 1$ yoksa öğretim amaçlı mı olduğu)' gibi faktörleri kapsamaktadır. Alt yapı; simülasyonun hedeflerini ve tasarımını etkileyen belirli çıktıları veya karş1laştırmaları içermektedir. Simülasyonun arka planında zaman ve ekipmanların yanı sira bu kaynakların nasıl kullanılacağı da açıklanmaktadır. Tasarım; simülasyon tasarımının bazı öğeleri simülasyon uygulama sirasında değiştirilebilmesine rağmen, simülasyon tasarımının oluşturulmasında dikkate alınması gereken ana unsurlar bulunmaktadır. Simülasyon tasarımı, senaryoların geliştirilmesine veya seçilmesine rehberlik eden özel öğrenme hedeflerini içermektedir. Fidelity (gerçeklik), ekipman, mulaj (moulage) ve uygulamalara yönelik kolaylaştırıcı yanıtları/ipuçları gibi fiziksel ve kavramsal bileşenler simülasyon tasarımında yer almaktadır. Ayrıca; katılımcı ve gözlemci rolleri senaryonun akışı, ön bilgilendirme ve çözümleme oturumu simülasyon tasarımının bir parçası olarak oluşturulmaktadır. Simülasyon Deneyimi; simülasyon deneyimsel, etkileşimli, işbirlikçi ve öğrenen merkezli güvenli bir ortam ile tanımlanmaktadır. Bu ortamda, hem kolaylaştırıcı hem de katılımc1 güvenli simülasyon ortamının sürdürülmesindeki sorumluluğu paylaşmaktadır. Kolaylaştırıcı ve Öğretim Stratejileri; bir simülasyon uygulamasında, kolaylaştırıcı ve katılımcı arasında dinamik bir etkileşim bulunmaktadır. Kolaylaştırıcı, simülasyon uygulamas1 boyunca katılımc1 gereksinimlerine eğitim 
stratejilerine göre geri bildirim vermektedir. Bunlar; uygulama sırasında, senaryonun akışında ve zamanlamadaki değişikliklerin planlanması, ipuçları şeklinde uygun geri bildirimlerin verilmesi ve çözümleme oturumunun yönetilmesini içermektedir. Katılımcl; katılımcı özellikleri simülasyon ile öğrenme yöntemini de etkilemektedir. Literatürde katılımcının özellikleri olarak yaş, cinsiyet, kaygı düzeyi, öz güven ve simülasyon uygulamasına yönelik hazırlığı gibi faktörler tanımlanmaktadır. Simülasyon tasarımının birçok öğesi katılımcıları ve öğrenme deneyimini etkileyebilmektedir. Sonuçlar; simülasyonun sonuçları katılımcı, hasta (bakım verilen) ve sistem çıktıları olmak üzere üç bölüme ayrılmıştır. Literatürde simülasyon çıktılarında katılımcıdaki; tepki (memnuniyet, öz güven), öğrenme (bilgi, beceri, tutum değişiklikleri) ve davranış (kliniğe öğrenilenlerin nasıl aktarıldığ 1 ) gibi sonuçlara odaklanılmaktadır. Bununla birlikte, simülasyonun maliyet etkinliği ve uygulama değişiklikleri ile ilgili sağlı sonuçlarını kapsayan simülasyon sonuçları da bulunmaktadır (3).

Yapılan çalışmalarda, simülasyon uygulamalarında bilgi kazanımı ve bilginin kalıcılığının sınıf içi geleneksel eğitim uygulamalarına göre daha etkili olduğu vurgulanmaktadır. Beceri kazanımı ise tekrarlanan simülasyonlar aracılığıyla öğrenilmekte olup etkinliği ortaya çıkmaktadır. Katılımcı memnuniyeti, eleştirel düşünme ve klinik karar verme gibi değişkenler ise nicel ve nitel değerlendirme araçları ile ölçülebilmektedir. $\mathrm{Bu}$ kapsamda simülasyon uygulamaları katılımcıların bilgi düzeyini, beceri performansını, eleştirel düşünme eğilimi ve problem çözmeye dayalı klinik karar verme becerilerini artırmaktadır (1).

\section{Sonuç ve Öneriler}

Hemşirelik eğitiminde öğrencilerin yetkinlik kazanabilmesi için teorik bilgilerin klinik uygulamalar ile birleştirilmesi önem taşımaktadır. Fakat klasik eğitim sisteminde bütün öğrencilerin öğrenme hedeflerini karşılayan standart bir uygulama deneyimi elde etmesi mümkün olmamaktadır. Simülasyona dayalı hemşirelik eğitimleri ise güvenli bir ortamda bütün öğrencilere, yetişkin öğrenme ilkelerinin etkili bir şekilde kullanıldığı yapılandırılmış bir klinik deneyim kazanma firsatı sunmaktadır. Yetişkinler için ise uygulayarak ya da gözlemleyerek öğrenmek önemli olup, klasik eğitim yöntemleri yetişkin öğrenmede yeterince etkili olmamaktadır. $\mathrm{Bu}$ durum günümüzde, hemşirelik eğitimine entegre edilmesine yönelik giderek artan bir biçimde çalışmaların yürütüldüğü simülasyona dayalı eğitimin önemi ortaya çıkarmaktadır.

Simülasyona dayalı eğitimlerin etkin bir öğrenme metodu olabilmesi için kuramlara dayandırılması önem taşımaktadır. Dolayısı ile yenilikçi bir öğretim stratejisi olan simülasyon eğitiminin en iyi uygulama standartları rehberliğinde hazırlanmas1 ve kuramsal alt yapının da ortaya koyularak bütüncül bir yaklaşımla planlanması önerilmektedir. Bu kapsamda tasarlanan, uygulanan ve değerlendirilmesi yapılan simülasyonların; profesyonel bir meslek olan hemşireliğin ilerlemesindeki önemli bir bileşen olan hemşirelik eğitiminin niteliğinin arttırılmasına katkı sağlayacağ düşünülmektedir.

\section{Kaynaklar}

1. Jeffries PR. A framework for designing, implementing and evaluating simulations used as teaching strategies in nursing. Nursing Education Perspectives 2005;26(2):96-103.

2. Jeffries PR, Rogers KJ. Theoretical framework for simulation design. Ed: Jeffries PR Simulation in nursing education: from conceptualization to evaluation. National League for Nursing. 2007. USA. 21-31.

3. Jeffries PR, Rodgers B, Adamson K. NLN Jeffries Simulation Theory: Brief Narrative Description. Nursing Education Perspective 2015;36(5):292-293.

4. Aebersold M, Tschannen D. Simulation in nursing practice: the impact on patient care OJIN: The Online Journal of Issues in Nursing 2013;18(2):6.

5. Kaakinen J. Arwood E. Systematic review of nursing simulation literatüre for use of learning theory. International Journal of Nursing Education Scholarship 2009;6(1):1-20.

6. V Ünver, T Basak. Simülasyona dayalı eğitimde senaryo yazma süreci. Türkiye Klinikleri Cerrahi Hastalıkları Hemşireliğgi Hemşirelikte Bilişim Özel Sayısı 2016;2(1):70-78.

7. The International Nursing Association for Clinical Simulation and Learning (INACSL). INACSL standards of best practice: Simulation_Simulation design. Clinical Simulation in Nursing 2016;12(Suplement):150. 
8. Bandura A. (Ed.). Self-efficacy in changin gsocieties. Cambridge, MA: Cambridge University Press. 1995.

9. Bandura A. Psychological modeling: Conflicting theories. NewBrunswick, NJ: Transactions (2006: original 1971).

10.Bayrakcı M. Sosyal öğrenme kuramı ve eğitimde uygulanmasi. SAÜ Eğitim Fakültesi Dergisi 2007;14:198-210.

11.Bahn D. Social Learning Theory: its application in the context of nurse education. Nurse Education Today 2001;21(2):110-117.

12.Christian A. Krumwiede N. Simulation enhances self-efficacy in the management of preeclampsia and eclampsia in obstetrical staff nurses. Clinical Simulation in Nursing 2013;9(9):369-377.

13.Driscoll MP. Psychology of learning for instruction 3th ed. London: Pearson; 2005. pp. $14-16$.

14.De Young S. Teaching Strategies for Nurse Educators. Upper Saddle River, NJ: Prentice Hal 2007.

15.Aliakbari F, Parvin N, Heidari M, Haghani F. Learning theories application in nursing education Journal of Education and Health Promotion 2015;4(2):1-11.

16.Phillips DC. The good, the bad, and the ugly: The many faces of constructivism. Educational Researcher 1995;4(7):5-12.

17.Phillips DC. How, why, what, when, andwhere: Perspectives on constructivism in psychology and education. Issues in Education 1997;3(2):151-195.

18.Baturay MH, Bay OF. The effects of problembased learning on the class-room community perceptions and achievement of web-based education students. Computers and Education 2010;55(1):43-52.

19.Lishchinsky OS. Simulation-based constructivist approach for education leaders. Educational Management Administration \&Leadership 2015;43(6):972-988.

20.Kolb DA. Experiential learning: Experience as the source of learning and development. Englewood Cliffs, 1984. NJ: PrenticeHall.

21.Poore JA, Cullen DL, Schaar GL. Simulation based interprofessional education guided by kolb'sexperiential learning theory. Clinical Simulation in Nursing 2014;10(5):241-247.
22.Doğan $\mathrm{P}$, Kuğuoğlu $\mathrm{S}$. Simülasyonda Kullanılan Eğitim Teorileri. Turkiye Klinikleri Journal of Pediatric Nursing Special Topics 2017;3(1):6-11.

23.Hemşirelik Ulusal Çekirdek Eğitim Programı (HUÇEP)2014

http://www.hemed.org.tr/images/

stories/hucep-2014-pdf.pdf. Erişim Tarihi: 04.03.2018.

24.Fawke J. Cusack J. Neonatal simulation training a work force for the future. Infant, 2011;7(1):9-11.

25.LeFlore J.L. Anderson M. Effectiveness of 2 methods to teach and evaluate new content to neonatal transport personnel usin ghigh-fidelity simulation. Journal of Perinatal and Neonatal Nursing, 2008;22(4):319-328.

26.Lindamood K.E. Weinstock P. Application of high-fidelity simulation training to the neonatal resuscitation and pediatric advanced life support programs. Newborn\&Infant Nursing Reviews, 2011;11(1):24-27.

27.Kaymakc1 S. Yeşiltaş NK. Education Understading of John Dewey and Some Sample Applications on the Education of Social Sciences. Journal of the Institute of Social Sciences 2009;4:227-242.

28.Lasater K. Clinical judgment development: Using simulation to create an assessment rubric. Journal of Nursing Education, 2007;46(11):496-503.

29.Reilly A. Spratt C. The perceptions of under graduate student nurses of high-fidelity simulation-based learning: A case report from the University of Tasmania. Nurse Education Today 2007;27(6):542-550.

30.Lathrop A, Sinningham B, VandeVusse L. Simulation-based learning for midwives: Background and pilot implementation. Journal of Midwifery \& Women's Health 2007;52(5):492-498.

31.Knowles M. S. The modern practice of adult education: From pedagogy to andragogy. 1980, Chicago, IL: Follett.

32. Knowles M. S. The adult learner: A neglected species. (4th ed.), 1990, Houston,TX: Gulf

33. Feingold CE, Calaluce $M$, Kallen MA. Computerized patient model and simulated clinical experiences: Evaluation with baccalaureate nursingstudents. Journal of Nursing Education 2004;43(4):156-163. 
34. Yaeger KA, Halamek LP, Coyle M, Murphy A, Anderson J, Boyle K, Braccia K, McAuley J, Sandre GD, Smith B. High-fidelity simulationbased training in neonatal nursing. Advances in NeonatalCare 2004;4(6):326-331.

35.Rutherford-Hemming T. Simulation methodology in nursing education and adult learning theory. Adult Learning 2012; 23(3).129-137.

36.Benner P From novice to expert: Excellence and power in clinical nursing practice. Menlo Park, CA: 1984. Addison-Wesley.

37.Thomas CM, Kellgren M. Benner's Novice to Expert Model: An application for simulation facilitators. Nursing Science Quarterly 2017;30(3):227-234.

38. Tanner C. A. Thinking like a nurse: A researchbased model of clinical judgment in nursing. Journal of Nursing Education 2006;45(6):204211.

39.Letcher DC. Roth SJ. Varenhorst LJ. Simulation-based learning: improving knowledge and clinical judgment within the NICU Clinical Simulation in Nursing 2017;13:284-290.

40.Sharof L. Simulation: Pre-briefing preparation, clinical judgment and reflection. What is the connection. Journal of Contemporary Medicine 2015;5(2):88-10 